\title{
Effect of one-stop hybrid coronary revascularization on postoperative renal function and bleeding: A comparison study with off-pump coronary artery bypass grafting surgery
}

\author{
Shan Zhou, MD, ${ }^{\mathrm{a}}$ Zhongrong Fang, MD, ${ }^{\mathrm{a}}$ Hui Xiong, MD, ${ }^{\mathrm{b}}$ Shengshou Hu, MD, ${ }^{\mathrm{b}}$ Bo Xu, MD, ${ }^{\mathrm{c}}$ \\ Lei Chen, MD, ${ }^{a}$ and Weipeng Wang, MD $^{\mathrm{a}}$
}

\begin{abstract}
Objectives: Although 1-stop hybrid coronary revascularization offers potential benefits for selected patients with multivessel coronary artery disease, the exposure to contrast dye and potent antiplatelet drugs could increase the risk of postoperative acute kidney injury and coagulopathy. The goal of the present study was to compare the measures of renal function, postoperative bleeding, and transfusion requirements in patients undergoing hybrid revascularization compared with off-pump coronary artery bypass grafting (CABG).
\end{abstract}

Methods: We retrospectively analyzed the data from 141 consecutive patients who had undergone 1-stop hybrid coronary revascularization from June 2007 to January 2011. Propensity score matching with 141 off-pump CABG patients from our surgical database was performed for comparison. The change in renal function, cumulative chest tube drainage, and clinical outcome parameters were compared between the 2 groups.

Results: Compared with off-pump CABG, patients undergoing hybrid revascularization had significantly less chest tube drainage at 12 hours after surgery $(P=.04)$ and for the total amount during the postoperative period $(P<.001)$ and required fewer blood transfusions $(P=.001)$. The hybrid group had a higher incidence of acute kidney injury, but this did not reach statistical significance $(25.2 \%$ vs $17.6 \%, P=.13)$. The hybrid group required less inotropic and vasoactive support, had fewer respiratory complications, required a shorter time of mechanical support, and had a decreased length of intensive care unit stay.

Conclusions: Compared with off-pump CABG, 1-stop hybrid coronary revascularization was associated with benefits such as less postoperative bleeding and blood transfusion requirements without significantly increasing the additional risk of acute kidney injury. (J Thorac Cardiovasc Surg 2014;147:1511-6)

Supplemental material is available online.

Hybrid coronary revascularization (HCR) has been defined as the combination of minimally invasive direct coronary artery bypass surgery and percutaneous coronary intervention (PCI) in selected patients with multivessel coronary artery disease. ${ }^{1-4}$ The potential advantages of HCR include the superior long-term patency of the surgical left internal mammary artery (LIMA) to left anterior descending artery (LAD) bypass graft ${ }^{5-7}$ and the benefits of PCI, especially

\footnotetext{
From the Departments of Anesthesiology, ${ }^{\mathrm{a}}$ Surgery, ${ }^{\mathrm{b}}$ and Cardiology, ${ }^{\mathrm{c}}$ State Key Laboratory of Translational Cardiovascular Medicine, Fuwai Hospital and Cardiovascular Institute, Chinese Academy of Medical Sciences, Peking Union Medical College, Beijing, People's Republic of China.

Disclosures: Authors have nothing to disclose with regard to commercial support.

Received for publication Feb 26, 2013; revisions received April 17, 2013; accepted

for publication May 23, 2013; available ahead of print July 22, 2013.

Address for reprints: Weipeng Wang, MD, Department of Anesthesiology, Fuwai Hospital and Cardiovascular Institute, 167, Beilishi Rd, Xicheng District, Beijing 100037, People's Republic of China (E-mail: wpwang63@hotmail.com). $0022-5223 / \$ 36.00$

Copyright (c) 2014 by The American Association for Thoracic Surgery http://dx.doi.org/10.1016/j.jtcvs.2013.05.026
}

with drug-eluting stents instead of saphenous vein grafts for non-LAD lesions. ${ }^{8-10}$ The term "1-stop HCR" has been used when the 2 procedures have been performed consecutively in the same setting, typically referred to as a "hybrid operating room." ${ }^{11,12}$ The suggested benefits of this new approach include improved efficiency and logistics, immediate angiographic confirmation of graft patency, and greater patient satisfaction. ${ }^{2,13}$ The potential risks of 1-stop HCR have been associated with the administration of potent antiplatelet drugs and exposure to contrast dye, raising concerns about coagulopathy and increased transfusion requirements and renal insufficiency, respectively. The goal of the present study was to examine whether 1-stop HCR increases the risk of postoperative bleeding and renal insufficiency compared with off-pump coronary artery bypass grafting (OPCABG).

\section{METHODS \\ Patient Selection \\ After institutional review board approval, we retrospectively collected data from 141 consecutive patients who had undergone 1-stop HCR at our institution from June 2007 to January 2011. Propensity score matching was used to select 141 patients from 3256 OPCABG patients with data recorded in our surgical database during the same period. The parameters used for matching were selected in accordance with the data readily}




\section{Abbreviations and Acronyms \\ AKI = acute kidney injury \\ HCR = hybrid coronary revascularization \\ ICU = intensive care unit \\ LAD $=$ left anterior descending coronary artery \\ LIMA $=$ left internal mammary artery \\ $\mathrm{OPCABG}=$ off-pump coronary artery bypass grafting \\ PCI = percutaneous coronary intervention}

available in our database: gender, age, body mass index, preoperative arterial hypertension, hyperlipidemia, diabetes mellitus, preoperative myocardial infarction, and left ventricular ejection fraction (Table 1). Additional parameters were collected and compared between the 2 groups after the primary matching process (Table 2 ).

The inclusion criteria for 1-stop HCR were the presence of multivessel coronary lesions demonstrated by coronary angiography, which involved a LAD lesion (or lesions) that was judged not suitable for PCI but was a suitable target for surgical grafting (eg, chronic total occlusion, severe calcification, ostial lesion, or proximal lesions) and non-LAD lesions that were suitable for PCI. Patients with previous sternotomy, LIMA stenosis, symptoms of congestive heart failure, or unstable hemodynamics (eg, preoperative pharmacologic or mechanical support), the need for concomitant cardiac surgery (eg, valve replacement or repair procedure), and patients with contradictions for PCI (eg, allergy to contrast dye) were excluded.

\section{Procedure}

A balanced general anesthesia technique with midazolam, etomidate or propofol, fentanyl or sufentanil, and vecuronium was used for induction, and a potent inhalational-based agent or propofol infusion were used for anesthesia maintenance.

For the 1-stop hybrid procedure, the patients first underwent minimally invasive direct coronary artery bypass surgery using a midline ministernotomy approach, followed by PCI for non-LAD lesions. Technically, a reversed-J inferior sternotomy was performed up to the left second intercostal space, and the LIMA was harvested with the assistance of a lift retractor under direct vision. Unfractionated heparin $(100-120 \mathrm{IU} / \mathrm{kg}$ body weight) was administered before harvesting the LIMA. Surgical anastomosis of the LIMA to LAD graft was performed using a stabilizer (Octopus, Medtronic Inc, Minneapolis, Minn) on the beating heart. Patients who did not tolerate OPCABG because of unstable hemodynamics were converted to on-pump surgery. After surgical LIMA to LAD anastomosis and chest closure, angiography was performed to confirm the patency of the LIMA-LAD graft. If any angiographic defects were identified, surgical revision was immediately performed. For the PCI procedure, access was established through the femoral artery using a previously described standard technique. $^{14}$

For the OPCABG procedure, a median sternotomy was performed in all patients. The LIMA and saphenous vein conduits were harvested under direct vision. The distal anastomoses of the LIMA to LAD and saphenous conduits to non-LAD target grafts were performed on the beating heart using a stabilizer (Octopus). The proximal anastomoses were accomplished with a partial occluding aortic clamp. Transonic flow measurements (Medi-Stim Butterfly System BF2004; Medi-Stim AS, Oslo, Norway) were performed in all patients to confirm graft patency after revascularization.

\section{Anticoagulation Protocol}

Details about the anticoagulation and, specifically, the antiplatelet regimen for hybrid procedures practiced in our institution have been previously published. ${ }^{15}$ Aspirin $100 \mathrm{mg}$ once daily was continued until the morning of surgery, and clopidogrel was discontinued $\geq 5$ to 7 days before surgery. Unfractionated heparin (100-120 IU/kg body weight) was administered intraoperatively to achieve an activated clotting time $>300$ seconds during the surgical procedure. After completion of the LIMA to LAD anastomosis, heparin was reversed with protamine sulfate in accordance with the results from a heparin-protamine titration assay. A loading dose of $300 \mathrm{mg}$ clopidogrel was administered through a nasogastric tube before the PCI procedure. Additional heparin (100 IU/kg body weight) was administered if the activated clotting time was $<200$ seconds during the $\mathrm{PCI}$ procedure. The maintenance antiplatelet regimen after the procedure consisted of $75 \mathrm{mg}$ clopidogrel once daily for $\geq 12$ months, and aspirin $300 \mathrm{mg}$ once daily for the first 30 days, followed by $100 \mathrm{mg}$ aspirin once daily for life.

For the OPCABG procedure, aspirin and clopidogrel were discontinued $\geq 5$ days before surgery. Also, $200 \mathrm{IU} / \mathrm{kg}$ body weight of unfractionated heparin was administered before harvesting the LIMA. Additional heparin was administered to maintain the activated clotting time $>300$ seconds throughout the whole procedure. After completion of all anastomoses, heparin was fully reversed with protamine sulfate.

\section{Data Collection}

The primary endpoints of the present study were to compare the incidence of postoperative bleeding and transfusion requirements and renal function between the 2 groups. Postoperative chest tube drainage was measured at 6 and 12 hours after the procedure, and the total cumulative chest tube drainage was recorded for the whole postoperative period. Serum creatinine was compared between the 2 groups for the first 3 postoperative days. If more than 1 serum creatinine value was available each day, the highest value was chosen for analysis. Acute kidney injury (AKI) was defined according to the Acute Kidney Injury Network criteria: serum creatinine increase $\geq 26.5 \mu \mathrm{mol} / \mathrm{L}$ or an increase to 1.5 -fold from baseline within 48 hours. ${ }^{16}$

The secondary endpoints were defined as the following postoperative clinical outcomes: mortality during the hospital stay, hemodynamic instability requiring the use of an intra-aortic balloon pump, hemodialysis, myocardial damage (defined as an increase in serum creatinine kinase to $>5$ times the upper normal $\operatorname{limit}^{17}$ ), new-onset atrial fibrillation, mechanical ventilation duration, respiratory insufficiency requiring endotracheal reintubation, abnormal postoperative chest radiographic findings such as atelectasis and pleural effusion, neurologic complications (eg, stroke or transient ischemia attack), emergency reoperation and resternotomy, length of stay in the intensive care unit (ICU), and postoperative hospital length of stay. Hemodynamic stability was assessed using the following 3 categories: hemodynamically stable (no vasoactive or inotropic drug administration), moderate hemodynamic instability (1-2 drugs), and unstable when $>3$ drugs were required intraoperatively or during the postoperative period in the ICU.

\section{Statistical Analysis}

Propensity score matching was performed using Statistical Analysis Systems software for Windows, version 9.2 (SAS Institute Inc, Cary, $\mathrm{NC}$ ). A predesigned SAS macro program was used for the propensity score algorithm, using an interval score $<0.01$ between the 2 groups to define a qualified match. If more than 1 OPCABG case was matched to a hybrid case, random selection was performed using the macro program.

The data are expressed as the mean \pm standard deviation, median, or percentage. For continuous variables, the Student $t$ test was used to measure the differences with a normal distribution and the Wilcoxon rank sum test was used for variables not normally distributed. Categorical variables were compared using the chi-square statistic or Fisher's exact test. Analysis of variance for repeated measures was used to measure differences between the measurement points (original data presented in Table E1). $P$ values $<.05$ were considered statistically significant. All statistical 
TABLE 1. Baseline variables used for propensity matching

\begin{tabular}{lccc}
\hline \multicolumn{1}{c}{ Variable } & $\begin{array}{c}\text { Hybrid } \\
(\mathbf{n = 1 4 1 )}\end{array}$ & $\begin{array}{c}\text { OPCABG } \\
(\mathbf{n}=\mathbf{1 4 1})\end{array}$ & $\boldsymbol{P}$ value \\
\hline Male gender & $125(88.7)$ & $126(89.4)$ & .85 \\
Age $(\mathrm{y})$ & $62 \pm 10.1$ & $63.2 \pm 8.5$ & .36 \\
BMI $\left(\mathrm{kg} / \mathrm{m}^{2}\right)$ & $25.9 \pm 4.2$ & $25.8 \pm 2.8$ & .85 \\
Arterial hypertension & $91(64.5)$ & $78(55.3)$ & .11 \\
Diabetes mellitus & $37(26.2)$ & $45(31.9)$ & .29 \\
Hyperlipidemia & $76(53.9)$ & $62(44)$ & .10 \\
Previous myocardial & $46(32.6)$ & $60(42.6)$ & .09 \\
$\quad$ infarction & & & \\
LVEF $(\%)$ & $61.83 \pm 6.9$ & $60.1 \pm 9.3$ & .07 \\
\hline
\end{tabular}

Data are presented as $\mathrm{n}(\%)$ or mean \pm standard deviation. Hybrid, One-stop hybrid coronary revascularization; $O P C A B G$, off-pump coronary artery bypass grafting; $B M I$, body mass index; $L V E F$, left ventricular ejection fraction.

analyses were performed using the Statistical Package for Social Sciences software package for Windows, version 16.0 (SPSS, Chicago, Ill).

\section{RESULTS}

All 141 patients in each group successfully underwent coronary revascularization. Of the patients in the hybrid group, 3 required conversion to on-pump LIMA to LAD graft anastomosis because of intraoperative hemodynamic instability. The baseline parameters were not statistically different between the 2 groups (Tables 1 and 2).

No significant difference was found in the amount of chest tube drainage between the 2 groups at 6 hours after surgery; however, the hybrid group had significantly less drainage at 12 hours $(P=.04)$ and less total cumulative postoperative chest tube drainage overall $(P<.001)$ (Figure 1). Additionally, the hybrid group had significantly

TABLE 2. Unmatched baseline variables

\begin{tabular}{lccc}
\hline \multicolumn{1}{c}{ Variable } & $\begin{array}{c}\text { Hybrid } \\
(\mathbf{n}=\mathbf{1 4 1})\end{array}$ & $\begin{array}{c}\text { OPCABG } \\
(\mathbf{n}=\mathbf{1 4 1})\end{array}$ & $\boldsymbol{P}$ value \\
\hline Previous PCI & $14(9.9)$ & $16(11.3)$ & .70 \\
Smoking history & $78(55.3)$ & $70(49.6)$ & .34 \\
COPD & $7(5)$ & $7(5)$ & 1.0 \\
EuroSCORE & $2.34 \pm 2.24$ & $2.6 \pm 2.16$ & .33 \\
Chronic renal insufficiency & $3(2.1)$ & $3(2.1)$ & 1.0 \\
Preoperative creatinine & $90.3 \pm 22.4$ & $84 \pm 17.9$ & .08 \\
$\quad(\mu$ mol/L) & $13(9.2)$ & $21(14.9)$ & .14 \\
Previous cerebrovascular & & & \\
$\quad$ disease & $31(22)$ & $34(24.1)$ & .67 \\
Peripheral vascular disease & $33(23.4)$ & $47(33.4)$ & .09 \\
LM disease & $141(100)$ & $140(99.3)$ & 1.0 \\
LAD disease & $92(65.2)$ & $127(90)$ & $<.001$ \\
LCx disease & $107(76)$ & $121(85.8)$ & .05 \\
RCA disease & $129(91.5)$ & $126(89.4)$ & .54 \\
$\beta$-Blocker medication &
\end{tabular}

Data are presented as $\mathrm{n}(\%)$ or mean \pm standard deviation. $P C I$, Percutaneous coronary intervention; COPD, chronic obstructive pulmonary disease; EuroSCORE, European system for cardiac operative risk evaluation; $L M$, left main coronary artery; $L A D$, left anterior descending coronary artery; $L C x$, left circumflex coronary artery; $R C A$, right coronary artery; Hybrid, one-stop hybrid coronary revascularization; $O P C A B G$, off-pump coronary artery bypass grafting.

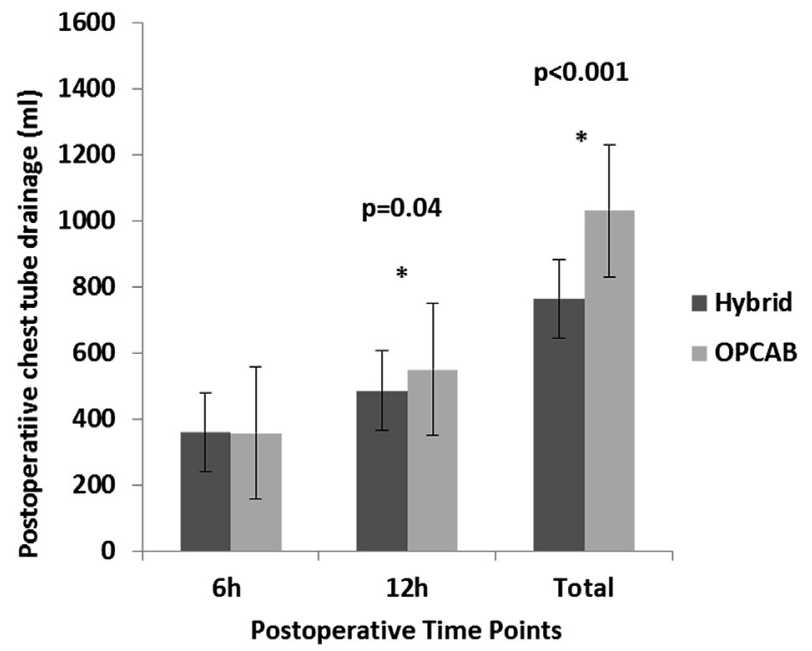

FIGURE 1. Postoperative bleeding in patients undergoing 1-stop hybrid coronary revascularization (hybrid) compared with off-pump coronary artery bypass grafting $(O P C A B G)$. ${ }^{*} P$ value refers to the comparison between the 1-stop hybrid coronary revascularization and OPCABG groups.

lower packed red blood cell and plasma transfusion rates compared with the OPCABG group $(21.3 \%$ vs $31.9 \%$, $P=.04$, and $9.9 \%$ vs $31.2 \%, P<.001$, respectively). No difference was found in the rate of platelet transfusion between the 2 groups (Table 3 ).

The serum creatinine levels increased significantly after surgery but showed a decreased tendency at ICU admission in both groups. The serum creatinine levels were higher in the hybrid group than in the OPCABG group at ICU admission $(P=.02$, Figure 2$)$, although none of the other measurement points showed significant differences. When applying the Acute Kidney Injury Network criteria to both groups, the hybrid group had a higher rate of acute kidney injury compared with the OPCABG group, but this did not reach statistical significance $(25.2 \%$ vs $17.6 \%, P=.13$; Table 3). None of the patients in the hybrid group and 2 patients in the OPCABG group required hemodialysis for acute renal dysfunction.

The secondary outcomes measures are presented in Table 3. Intraoperatively, the hybrid group had significantly longer anesthesia and surgical times but fewer inotropic drug requirements (Table 3). Postoperatively, 1 patient died of cardiac arrest in the hybrid group, and 2 patients died of postoperative multiorgan dysfunction in the OPCABG group. The patients who underwent the 1-stop hybrid procedure had fewer pulmonary complications (atelectasis and/or pleural effusion on the chest radiograph), fewer vasoactive and inotropic drug requirements, required less mechanical ventilation, and a shorter ICU length of stay compared with the OPCABG group (Table 3). No significant differences were found in the postoperative hospital length of stay, intra-aortic balloon pump requirement, myocardial damage determined by creatinine kinase, reoperation, endotracheal 
TABLE 3. Intraoperative and postoperative clinical outcomes between hybrid and OPCABG groups

\begin{tabular}{|c|c|c|c|}
\hline Variable & $\begin{array}{c}\text { Hybrid } \\
(\mathrm{n}=141)\end{array}$ & $\begin{array}{l}\text { OPCABG } \\
(\mathbf{n}=141)\end{array}$ & $P$ value \\
\hline \multicolumn{4}{|l|}{ Intraoperative comparison } \\
\hline Anesthesia time (min) & $304.5 \pm 75.5$ & $239.4 \pm 43.2$ & $<.001$ \\
\hline Operative time (min) & $248.5 \pm 73.4$ & $199.4 \pm 43.2$ & $<.001$ \\
\hline Urine output (mL) & $639.2 \pm 484$ & $349.8 \pm 265.6$ & $<.001$ \\
\hline Fluid infusion (mL) & $1167.2 \pm 453$ & $1324.8 \pm 440$ & .003 \\
\hline $\begin{array}{l}\text { Intraoperative vasoactive } \\
\text { drugs (n) }\end{array}$ & & & .005 \\
\hline 0 & $26(18.4)$ & $11(7.8)$ & \\
\hline $1-2$ & $115(81.5)$ & $126(89.4)$ & \\
\hline$>3$ & $0(0)$ & $4(2.8)$ & \\
\hline \multicolumn{4}{|l|}{ Postoperative comparison } \\
\hline Mortality & $1(0.71)$ & $2(1.41)$ & 1.0 \\
\hline IABP & $0(0)$ & $2(1.41)$ & .50 \\
\hline Myocardial damage & $5(3.5)$ & $7(5.4)$ & .45 \\
\hline Dialysis & $0(0)$ & $2(1.41)$ & .50 \\
\hline Acute kidney injury & $35(25.2)$ & $23(17.6)$ & .13 \\
\hline Reoperation & $4(2.8)$ & $8(5.6)$ & .24 \\
\hline Reintubation & $2(1.41)$ & $1(0.71)$ & 1.0 \\
\hline Neurologic event & $1(0.71)$ & $1(0.71)$ & 1.0 \\
\hline Atelectasis & $25(17.7)$ & $54(38.3)$ & $<.001$ \\
\hline Pleural effusion & $8(5.7)$ & $19(13.5)$ & .03 \\
\hline $\begin{array}{l}\text { New-onset atrial } \\
\text { fibrillation }\end{array}$ & $24(17)$ & $14(9.9)$ & .08 \\
\hline $\begin{array}{l}\text { Mechanical ventilation } \\
\text { time (h) }\end{array}$ & $12.9 \pm 11$ & $18.3 \pm 18.2$ & .003 \\
\hline ICU stay (h) & $34.8 \pm 33.1$ & $45.6 \pm 37.3$ & .01 \\
\hline $\begin{array}{l}\text { Postoperative hospital } \\
\text { stay (d) }\end{array}$ & $8.19 \pm 2.54$ & $8.49 \pm 3.53$ & .41 \\
\hline ICU vasoactive drugs (n) & & & .04 \\
\hline 0 & $0(0)$ & $1(0.71)$ & \\
\hline $1-2$ & $113(80.1)$ & $95(67.4)$ & \\
\hline$>3$ & $28(19.9)$ & 45 (31.9) & \\
\hline $\begin{array}{l}\text { Packed } \mathrm{RBC} \text { transfusion } \\
\text { rate }\end{array}$ & $30(21.3)$ & 45 (31.9) & .04 \\
\hline Plasma transfusion rate & $14(9.9)$ & $44(31.2)$ & $<.001$ \\
\hline Platelet transfusion rate & $1(0.7)$ & $3(2.1)$ & .62 \\
\hline
\end{tabular}

Data are presented as mean \pm standard deviation or $\mathrm{n}(\%)$. IABP, Intra-aortic balloon pump; $I C U$, intensive care unit; $R B C$, red blood cells; Hybrid, one-stop hybrid coronary revascularization; $O P C A B G$, off-pump coronary artery bypass grafting.

reintubation, new-onset atrial fibrillation, or adverse neurologic events between the 2 groups.

\section{DISCUSSION}

One-stop HCR offers potential benefits for patients presenting for complex coronary revascularization. ${ }^{3,18,19}$ Concerns have been raised, however, about an increased risk of postoperative bleeding and renal dysfunction with this approach. ${ }^{2,20}$ The findings from the present study have suggested that 1-stop HCR did not increase the risk of postoperative bleeding and renal dysfunction compared with OPCABG surgery. Although exposed to a potent

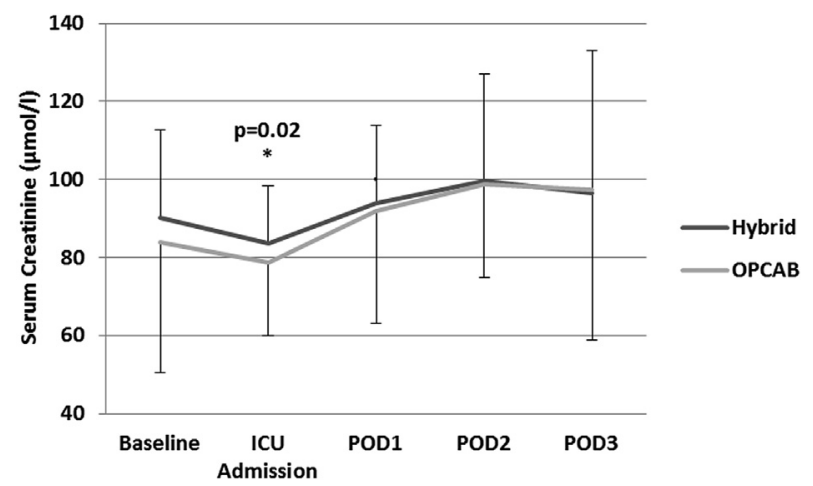

FIGURE 2. Serum creatinine in patients undergoing 1-stop hybrid coronary revascularization compared with off-pump coronary artery bypass grafting $(O P C A B G)$ patients. $* P$ value refers to comparison between 1 -stop hybrid coronary revascularization and OPCABG. $P O D$, Postoperative day.

antiplatelet drug regimen, the hybrid patients actually had less bleeding and required fewer blood transfusions compared with the OPCABG group.

The results of decreased postoperative bleeding and transfusion requirements might have resulted from the less invasive nature of the hybrid approach. ${ }^{19}$ Fewer surgical anastomoses are needed because of stent placement, and a smaller surgical incision is typically used for the minimally invasive direct coronary artery bypass approach in the hybrid group compared with the complete midline sternotomy in the OPCABG group. However, the optimal antiplatelet regimen for patients undergoing HCR has not been established. Some studies have adopted $600 \mathrm{mg}$ clopidogrel in HCR setting ${ }^{21,22}$; however, despite better inhibition of platelet activity, postoperative excessive bleeding poses a major concern. The goal of antiplatelet therapy for patients undergoing HCR is to inhibit platelet activity to preserve stent patency and to minimize the risk of postoperative bleeding. Although controversial at first, the specific choice of antiplatelet drugs and the exact timing of drug administration are crucial and could explain some of the controversial findings from previous studies. Our result of decreased postoperative bleeding after HCR correlated with the findings from Reicher et al, ${ }^{11}$ who administered $300 \mathrm{mg}$ clopidogrel on ICU arrival. Zhao et $\mathrm{al}^{4}$ found no difference in postoperative chest tube drainage when conventional CABG surgery was compared with HCR, which included the administration of $300 \mathrm{mg}$ clopidogrel before entering the operating room. These data suggest that for patients undergoing HCR, high-dose clopidogrel given after the surgical part of the procedure might have less effect on hemostasis compared with preoperative drug administration. ${ }^{23}$

In our study, the contrast dye used for the interventional part of the hybrid procedure was not associated with renal dysfunction. Both cardiac surgery and the administration 
of contrast dye during PCI are well known to increase the risk of renal dysfunction. ${ }^{24,25}$ We had hypothesized that the incidence of acute kidney injury would be greater in patients undergoing HCR compared with those undergoing OPCABG alone. Previous investigations have reported controversial findings. Kon et $\mathrm{al}^{3}$ reported a lower rate of postoperative renal insufficiency after HCR compared with OPCABG $(0 \%$ vs $10 \%)$, defined as an increase in creatinine of $>25 \%$ greater than baseline, and Halkos et $\mathrm{al}^{26}$ found no difference in renal failure between HCR and OPCABG. The different outcome definitions could partly explain the inconsistent results. Zhao et $\mathrm{al}^{4}$ reported no significant differences in serum creatinine values within 3 days after surgery between the 2 groups; however, their entire cohort underwent intraoperative completion angiography, increasing the risk of AKI for both groups. In the present study, we observed a slightly greater AKI rate compared with that after OPCABG, but the difference not reach statistical significance, and the serum creatinine levels did not differ significantly between the 2 groups during the observed study period. The reason could be that the more stable hemodynamics and better urine output in the hybrid group contributed to the nondetection of differences in AKI in the present study. ${ }^{27}$

We also found significantly fewer respiratory complications, a shorter time required for mechanical ventilation, and a shorter ICU length of stay in the hybrid group. The lower atelectasis rate in the hybrid group might have been related to the minithoracotomy surgical approach, ${ }^{28}$ and the higher pleural effusion rate in OPCABG group might have been related to the surgical trauma and more fluid administration during surgery.

\section{Study Limitations}

A major limitation of the present study was the retrospective study design. Additionally, although propensity matching was used, patient selection bias could not be fully excluded. The relatively small sample size and only shortterm follow-up were additional limitations.

\section{CONCLUSIONS}

One-stop HCR did not increase the rate of postoperative bleeding or AKI compared with OPCABG in our study population. Additional randomized and multicenter studies are warranted to more conclusively establish the risk and benefits associated with 1-stop HCR.

The authors would like to thank Dr Yang Wang from the Department of Statistics, Fuwai Hospital, Cardiovascular Institute, for his kindly contribution in statistical work in our study.

\section{References}

1. de Canniere D, Jansens JL, Goldschmidt-Clermont P, Barvais L, Decroly P, Stoupel E. Combination of minimally invasive coronary bypass and percutane- ous transluminal coronary angioplasty in the treatment of double-vessel coronary disease: two-year follow-up of a new hybrid procedure compared with “on-pump" double bypass grafting. Am Heart J. 2001;142:563-70.

2. Byrne JG, Leacche M, Vaughan DE, Zhao DX. Hybrid cardiovascular procedures. JACC Cardiovasc Interv. 2008;1:459-68.

3. Kon ZN, Brown EN, Tran R, Joshi A, Reicher B, Grant MC, et al. Simultaneous hybrid coronary revascularization reduces postoperative morbidity compared with results from conventional off-pump coronary artery bypass. $J$ Thorac Cardiovasc Surg. 2008;135:367-75

4. Zhao DX, Leacche M, Balaguer JM, Boudoulas KD, Damp JA, Greelish JP, et al. Routine intraoperative completion angiography after coronary artery bypass grafting and 1-stop hybrid revascularization results from a fully integrated hybrid catheterization laboratory/operating room. J Am Coll Cardiol. 2009;53:232-41.

5. BARI Investigators. The final 10-year follow-up results from the BARI randomized trial. J Am Coll Cardiol. 2007;49:1600-6.

6. Serruys PW, Ong AT, van Herwerden LA, Sousa JE, Jatene A, Bonnier JJ, et al. Five-year outcomes after coronary stenting versus bypass surgery for the treatment of multivessel disease: the final analysis of the Arterial Revascularization Therapies Study (ARTS) randomized trial. J Am Coll Cardiol. 2005;46:575-81.

7. Kiaii B, McClure RS, Stewart P, Rayman R, Swinamer SA, Suematsu Y, et al. Simultaneous integrated coronary artery revascularization with long-term angiographic follow-up. J Thorac Cardiovasc Surg. 2008;136:702-8.

8. Moses JW, Leon MB, Popma JJ, Fitzgerald PJ, Holmes DR, O'Shaughnessy C, et al. Sirolimus-eluting stents versus standard stents in patients with stenosis in a native coronary artery. $N$ Engl J Med. 2003;349:1315-23.

9. Murphy GJ, Bryan AJ, Angelini GD. Hybrid coronary revascularization in the era of drug-eluting stents. Ann Thorac Surg. 2004;78:1861-7.

10. Hannan EL, Wu C, Walford G, Culliford AT, Gold JP, Smith CR, et al. Drug eluting stents vs. coronary-artery bypass grafting in multivessel coronary disease. N Engl J Med. 2008;358:331-41.

11. Reicher B, Poston RS, Mehra MR, Joshi A, Odonkor P, Kon Z, et al. Simultaneous "hybrid" percutaneous coronary intervention and minimally invasive surgical bypass grafting: feasibility, safety, and clinical outcomes. Am Heart J. 2008; 155:661-7.

12. Halkos ME, Rab ST, Vassiliades TA, Morris DC, Douglas JS, Kilgo PD, et al. Hybrid coronary revascularization versus off-pump coronary artery bypass for the treatment of left main coronary stenosis. Ann Thorac Surg. 2011;92:2155-60.

13. Jaik NP, Umakanthan R, Leacche M, Solenkova N, Balaguer JM, Hoff SJ, et al Current status of hybrid coronary revascularization. Expert Rev Cardiovasc Ther. 2011;9:1331-7.

14. Yang YJ, Xu B, Chen JL, Kang S, Qiao SB, Qin XW, et al. Comparison of immediate and followup results between transradial and transfemoral approach for percutaneous coronary intervention in true bifurcational lesions. Chin Med J (Engl). 2007;120:539-44.

15. Gao P, Xiong H, Zheng Z, Li L, Gao R, Hu SS. Evaluation of antiplatelet effects of a modified protocol by platelet aggregation in patients undergoing "one-stop" hybrid coronary revascularization. Platelets. 2010;21:183-90.

16. Ronco C, Levin A, Warnock DG, Mehta R, Kellum JA, Shah S, et al. Improving outcomes from acute kidney injury (AKI): report on an initiative. Int $J$ Artif Organs. 2007;30:373-6.

17. Thygesen K, Alpert JS, White HD. Universal definition of myocardial infarction. J Am Coll Cardiol. 2007;50:2173-95.

18. Hu S, Li Q, Gao P, Xiong H, Zheng Z, Li L, et al. Simultaneous hybrid revascularization versus off-pump coronary artery bypass for multivessel coronary artery disease. Ann Thorac Surg. 2011;91:432-8.

19. Vassiliades TA, Kilgo PD, Douglas JS, Babaliaros VC, Block PC, Samady H, et al. Clinical outcomes after hybrid coronary revascularization versus offpump coronary artery bypass: a prospective evaluation. Innovations (Phila). 2009;4:299-306.

20. Byrne JG, Leacche M, Unic D, Rawn JD, Simon DI, Rogers CD, et al. Staged initial percutaneous coronary intervention followed by valve surgery ("hybrid approach") for patients with complex coronary and valve disease. J Am Coll Cardiol. 2005;45:14-8.

21. L'Allier PL, Ducrocq G, Pranno N, Noble S, Ibrahim R, Gregoire JC, et al. Clopidogrel 600-mg double loading dose achieves stronger platelet inhibition than conventional regimens: results from the PREPAIR randomized study. J Am Coll Cardiol. 2008;51:1066-72.

22. Gladding P, Webster M, Zeng I, Farrell H, Stewart J, Ruygrok P, et al. The antiplatelet effect of higher loading and maintenance dose regimens of clopidogrel the PRINC (Plavix Response in Coronary Intervention) trial. JACC CardiovasC Interv. 2008;1:612-9. 
23. Halkos ME, Cooper WA, Petersen R, Puskas JD, Lattouf OM, Craver JM, et al. Early administration of clopidogrel is safe after off-pump coronary artery bypass surgery. Ann Thorac Surg. 2006;81:815-9.

24. Surgenor SD, Kramer RS, Olmstead EM, Ross CS, Sellke FW, Likosky DS, et al. The association of perioperative red blood cell transfusions and decreased long-term survival after cardiac surgery. Anesth Analg. 2009;108: 1741-6.

25. McIlroy DR, Epi MC, Argenziano M, Farkas D, Umann T. Acute kidney injury after cardiac surgery: does the time interval from contrast administration to surgery matter? J Cardiothorac Vasc Anesth. 2012;26:804-12.
26. Halkos ME, Vassiliades TA, Douglas JS, Morris DC, Rab ST, Liberman HA, et al. Hybrid coronary revascularization versus off-pump coronary artery bypass grafting for the treatment of multivessel coronary artery disease. Ann Thorac Surg. 2011;92:1695-701; discussion 1701, 1692.

27. Weir MR, Aronson S, Avery EG, Pollack CV Jr. Acute kidney injury following cardiac surgery: role of perioperative blood pressure control. Am J Nephrol. 2011;33:438-52.

28. Ortiz LD, Schaan CW, Leguisamo CP, Tremarin K, Mattos WL, Kalil RA, et al. [Incidence of pulmonary complications in myocardial revascularization]. Arq Bras Cardiol. 2010;95:441-6. 
TABLE E1. Serum creatinine in hybrid and OPCABG groups at different measurement points (original data from Figure 2)

\begin{tabular}{lccc}
\hline Serum creatinine $(\boldsymbol{\mu} \mathbf{m o l} / \mathbf{L})$ & Hybrid $(\mathbf{n}=\mathbf{1 4 1})$ & OPCABG $(\mathbf{n}=\mathbf{1 4 1})$ & $\boldsymbol{P}$ value* \\
\hline Baseline & $90.26 \pm 22.4$ & $84 \pm 33.4$ & $78.68 \pm 18.7$ \\
ICU admission & $83.53 \pm 14.8$ & $91.83 \pm 28.7$ & .04 \\
POD 1 & $93.86 \pm 20$ & $98.73 \pm 23.7$ & .01 \\
POD 2 & $99.54 \pm 27.6$ & $97.28 \pm 38.5$ & .02 \\
POD 3 & $96.48 \pm 36.4$ & .04 \\
\hline
\end{tabular}

Data are presented as mean \pm standard deviation. Hybrid, One-stop hybrid coronary revascularization; $O P C A B G$, off-pump coronary artery bypass grafting; $I C U$, intensive care unit; $P O D$, postoperative day. ${ }^{*} P$ value refers to comparison with baseline serum creatinine according to repeated measurement results. 